\title{
パラジウム触媒アミノ化反応を基盤とする効率的インダゾール合成法の開発と応用
}

\author{
稲本 浄文
}

\section{Novel Access to Indazoles Based on Palladium-Catalyzed Amination Chemistry}

\author{
Kiyofumi INAMOTO \\ Graduate School of Pharmaceutical Sciences, Tohoku University, \\ 6-3 Aoba, Aramaki, Aoba-ku, Sendai 980-8578, Japan
}

(Received February 18, 2008)

\begin{abstract}
Two efficient methods to construct the indazole nucleus have been developed, both of which utilize palladium-catalyzed intramolecular carbon-nitrogen bond formation. One is based on intramolecular Buchwald-Hartwig amination reaction of 2-halobenzophenone tosylhydrazones. The catalyst system we developed for this reaction allows the cyclization to proceed under very mild conditions and thus could be applied to a wide range of substrates with acid- or base-sensitive functional groups. Furthermore, this methodology could be applied for the construction of benzoisoxazole ring system. In addition, catalytic $\mathrm{C}-\mathrm{H}$ activation with palladium followed by intramolecular amination of benzophenone tosylhydrazones was also accomplished with the aid of the catalyst system such as $\mathrm{Pd}(\mathrm{OAc})_{2} / \mathrm{Cu}(\mathrm{OAc})_{2} / \mathrm{AgOCOCF}_{3}$, which gave another route to indazoles. Using this combination, indazoles with various functional groups could be obtained in good to high yields, especially in the case of substrates having electron donating group such as methoxy group on benzene ring. Interesting chemo- and regioselectivity were also observed in this reaction.
\end{abstract}

Key words_— palladium; amination; indazole; carbon-hydrogen bond activation; silver salt

\section{1.はじめに}

含窒素複素環化合物は，医薬品，生理活性天然 物，及び機能性物質の母核として数多く存在してお り，古くからそれらの合成・反応性に関する研究は 活発に行われてきた。 そのため，この分野は基礎研 究としてほぼ完成した領域であると考えられる一面 もある。しかしながら，真の意味での「実用性」及 び「効率性」を兼ね備えた複素環調製法，具体的に は, 安価な出発原料から簡便な手法により合成で き，かつ高い官能基共存性及び化学選択性を有して いる方法はほとんど存在しないのが現状である。つ まり，既存の複素環構築に関しても，望む位置への 選択的官能基導入が可能となる新規反応の開発が今 なお強く求められているのである.

含窒素複素環化合物の 1 つであるインダゾール類 は，インドール類の bioisoster（生物学的等配電子

東北大学大学院薬学研究科（T980-8578 仙台市青葉区 荒巻字青葉 6-3)

e-mail: inamoto@mail.pharm.tohoku.ac.jp

本総説は, 平成 19 年度日本薬学会東北支部奨励賞の受 賞を記念して記述したものである.
体）として位置付けられる化合物群である（Fig. 1). インドール類と同様に幅広い生理活性を示すこ とが知られており, 多くの医薬品及び医薬品候補の

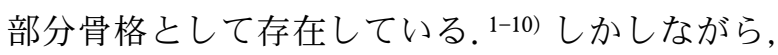
それらの合成研究は，インドールと比べてこれまで あまり検討されていない. いくつかの報告がある古 典的合成法11-13)においては，反応条件が苛酷であつ たり，またときとして有毒な金属試薬を当量以上用 いたりしなければならず，多様なインダゾール化合 物を系統的に得る一般的手法とは言い難い。一方, 近年になって，パラジウム触媒アミノ化反応を用い たインダゾール合成法が何例か報告されてい る.14-16）しかしこれらもまた，反応条件が比較的過 酷であるため, 官能基共存性に問題を残しており, さらに医薬品の母核として特に重要である 3 位置換 インダゾール類は，これらの手法から調製すること はできない.

筆者は，「分子内 Buchwald-Hartwig アミノ化反 応 $(\mathrm{C}-\mathrm{X}$ アミノ化反応)」と「炭素-水素結合活性 化一分子内アミノ化反応 $(\mathrm{C}-\mathrm{H}$ アミノ化反応 $) 」 と$ いう 2 つハパラジウム触媒を用いた手法により，対 
<smiles>CCCOC(C)CCOC(C)CC</smiles>

Fig. 1. Indole and Indazole

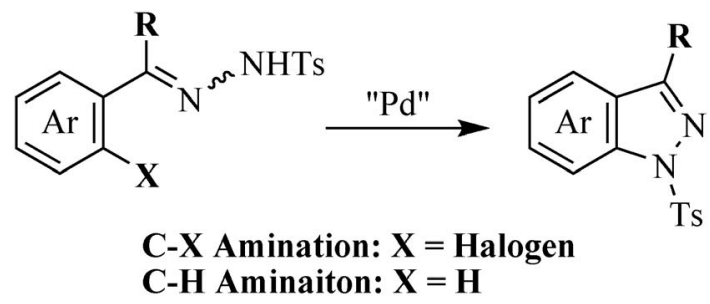

Fig. 2. Pd-Catalyzed Amination Reactions for Indazoles Synthesis

応するヒドラゾン類から効率的に 3 位置換インダ ゾール類が得られることを見い出したので, ${ }^{17-19)}$ そ の詳細について以下に述べる（Fig. 2).

2. 分子内 Buchwald-Hartwig アミノ化反応を利 用したインダゾール合成 ${ }^{17,18)}$

パラジウム触媒による炭素-窒素結合形成反応 (Buchwald-Hartwig アミノ化反応， $\mathrm{C}-\mathrm{X}$ アミノ化 反応）は，芳香族アミン化合物を合成するのに非常 に有用な手法であり，その発見以降，多くの有機合

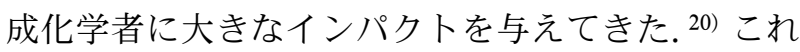
までに，新規配位子の合成を含めて，数多くの高活 性触媒系が開発されてきており，それらを用いるこ とで，反応性の低い芳香族塩化物や立体障害の大き い基質の反応が穏和な条件化，円滑に進行すること が示されてきた．本法を分子内反応に適用すること で含窒素複素環化合物合成を行えることになるが， 意外なことに，そのような分子内反応に関する報告 例は分子間反応に比べて非常に限られており，特に 官能基共存性や基質一般性といった点において, 解 決すべき問題点は多い.

2-1. 反応条件の最適化と基質適用範囲の検討 上述の背景を基に，筆者は，より系統的かつ実用 的な 3 位置換インダゾール類合成法の開発を目的と して，様々な 2-ハロフェニルケトンから容易に調 製可能なヒドラゾン類の，分子内パラジウム触媒ア ミノ化反応を用いた 3 位置換インダゾール類合成を 行うことにした（X=Halogen in Fig. 2).
官能基共存性の高い反応系を構築するため，可能 な限り穏和な条件下進行する反応条件の探索を広範 に行った。その結果, 二座配位子である $\mathrm{dppp} や$ dppf を，また塩基として $\mathrm{Cs}_{2} \mathrm{CO}_{3}$ や $\mathrm{NaO}^{t} \mathrm{Bu}$ を用 いることで, 本閉環反応が室温から $50^{\circ} \mathrm{C}$ とうう非 常に穏和な条件下, 円滑に進行することを見い出し た。このとき，溶媒として dioxane を用いることが 必須であり，またパラジウム錯体としては $\mathrm{Pd}(\mathrm{OAc})_{2}$ が優れていることが明らかとなった。様 々な置換基を有するヒドラゾン類 $\mathbf{1}$ のパラジウム触 媒閉環反応の結果を Table 1 にまとめた. はじめに 芳香族臬化物の反応を行ったが，インダゾールの 3 位がアルキル基となるような基質 1a からは, 高収 率で閉環体 2a が得られた (Entry 1)。加えて，ア ルコキシカルボニル基（Entry 2）やカルバモイル 基（Entry 3）といった官能基も，本反応条件下, 共存可能であることが明らかとなった，その他, ベ ンゼン環上に種々の置換基が存在する場合（Entries 5-8）等，おおむね良好な収率で目的とするイ ンダゾール類が得られた。 さらに, 擬ハロゲン化物 である芳香族ノナフレート (1i, Entry 9, ArONf= $\left.\mathrm{ArOSO}_{2}\left(\mathrm{CF}_{2}\right)_{3} \mathrm{CF}_{3}\right)^{21)}$ や芳香族塩化物 (1j, Entry 10）も本閉環反応に適用可能であった.

2-2. 炭素-酸素結合形成反応への応用によるべ ンゾイソキサゾール環構築上述の触媒系をオキ シム類へ適用することで, 同様の閉環プロセスを経 由して，3 位置換ベンズイソキサゾール類も合成で きることが分かった（Table 2)。例えば，3-phenylbenzoisoxazole 4a は, ${ }^{\mathrm{t}} \mathrm{BuONa} / \mathrm{Pd}(\mathrm{OAc})_{2} / \mathrm{dppf}$ と いう組み合わせを用いることによって, 対応するオ キシム 3aより $72 \%$ の収率で得られた（Entry 1)。 同様の芳香族ブロミドの反応では, ベンゼン環上に 電子求引性基が存在する場合には高収率で閉環体を 与えるが (Entry 3$)$, 逆に電子供与性基により反応 は抑制される (Entries 4 and 5)。残念ながら，この オキシム類のパラジウム触媒閉環反応における芳香 族ノナフレート 3d の反応性は非常に低かった (Entries 6 and 7)。一方で芳香族クロリド 3e から は，やや高い反応温度を必要とするものの，目的と するベンゾイソキサゾール $4 \mathrm{e}$ が収率よく得られた (Entry 8).

2-3. 分子内パラジウム触媒 $\mathbf{C}-\mathbf{X}$ アミノ化反応 を鍵とする天然物 Nigellicine の全合成、インダ 
Table 1. Intramolecular Pd-Catalyzed Amination of Hydrazones for Indazoles Synthesis ${ }^{a}$ )

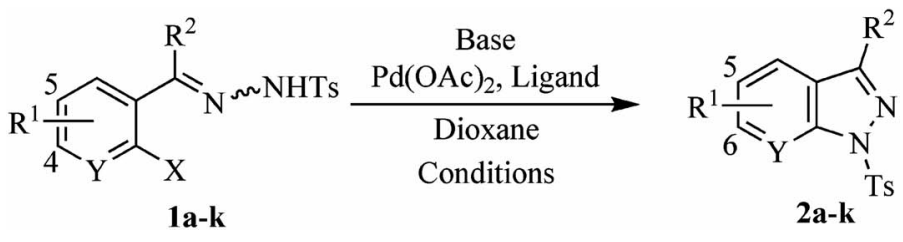

\begin{tabular}{ccccccccc}
\hline \hline Entry & $\mathbf{1}^{b)}$ & $\mathrm{X}$ & $\mathrm{Y}$ & $\mathrm{R}^{1}$ & $\mathrm{R}^{2}$ & Base/Ligand & Conditions & Yield (\%) \\
\hline 1 & $\mathbf{1 a}$ & $\mathrm{Br}$ & $\mathrm{CH}$ & $\mathrm{H}$ & ${ }^{\mathrm{i}} \mathrm{Pr}$ & $\mathrm{Cs}_{2} \mathrm{CO}_{3} / \mathrm{dppf}$ & $\mathrm{rt}, 7 \mathrm{~h}$ & $82(\mathbf{2 a})$ \\
2 & $\mathbf{1 b}-E$ & $\mathrm{Br}$ & $\mathrm{CH}$ & $\mathrm{H}$ & $\mathrm{CO}_{2}{ }^{\mathrm{B}} \mathrm{Bu}$ & $\left.\mathrm{Cs}_{2} \mathrm{CO}_{3} / \mathrm{P}(2-\mathrm{Tol})_{3}{ }^{c}\right)$ & $\mathrm{rt}, 3 \mathrm{~h}$ & $81(\mathbf{2 b})$ \\
3 & $\mathbf{1 c}-E$ & $\mathrm{Br}$ & $\mathrm{CH}$ & $\mathrm{H}$ & $\mathrm{CONEt}_{2}$ & ${ }^{\mathrm{t}} \mathrm{BuONa} / \mathrm{dppf}$ & $50^{\circ} \mathrm{C}, 17 \mathrm{~h}$ & $72(\mathbf{2 c})$ \\
4 & $\mathbf{1 d}$ & $\mathrm{Br}$ & $\mathrm{CH}$ & $\mathrm{H}$ & $\mathrm{Ph}$ & ${ }^{\mathrm{t}} \mathrm{BuONa} / \mathrm{dppp}$ & $50^{\circ} \mathrm{C}, 17 \mathrm{~h}$ & $83(\mathbf{2 d})$ \\
5 & $\mathbf{1}$ & $\mathrm{Br}$ & $\mathrm{CH}$ & $4-\mathrm{NO}_{2}$ & $\mathrm{Ph}$ & $\mathrm{Cs}_{2} \mathrm{CO}_{3} / \mathrm{dppf}$ & $50^{\circ} \mathrm{C}, 12 \mathrm{~h}$ & $74\left(\mathbf{2 e}: \mathrm{R}^{1}=6-\mathrm{NO}_{2}\right)$ \\
6 & $\mathbf{1 f}$ & $\mathrm{Br}$ & $\mathrm{CH}$ & $5-\mathrm{OMe}$ & $\mathrm{Ph}$ & ${ }^{\mathrm{t}} \mathrm{BuONa} / \mathrm{dppp}$ & $50^{\circ} \mathrm{C}, 2 \mathrm{~h}$ & $56\left(\mathbf{2 f}: \mathrm{R}^{1}=5-\mathrm{OMe}\right)$ \\
7 & $\mathbf{1 g}$ & $\mathrm{Br}$ & $\mathrm{CH}$ & $4-\mathrm{Me}$ & $\mathrm{Ph}$ & ${ }^{\mathrm{t}} \mathrm{BuONa} / \mathrm{dppf}$ & $50^{\circ} \mathrm{C}, 15 \mathrm{~h}$ & $66\left(\mathbf{2 g}: \mathrm{R}^{1}=6-\mathrm{Me}\right)$ \\
8 & $\mathbf{1 h}$ & $\mathrm{Br}$ & $\mathrm{CH}$ & $\mathrm{H}$ & $4-(\mathrm{MeO}) \mathrm{C}_{6} \mathrm{H}_{4}$ & ${ }^{\mathrm{t}} \mathrm{BuONa} / \mathrm{dppf}$ & $\mathrm{rt}, 8 \mathrm{~h}$ & $94(\mathbf{2 h})$ \\
9 & $\mathbf{1 i}$ & $\mathrm{ONf}$ & $\mathrm{CH}$ & $\mathrm{H}$ & $\mathrm{Ph}$ & $\mathrm{Cs}_{2} \mathrm{CO} / \mathrm{dppf}$ & $\mathrm{rt}, 2 \mathrm{~h}$ & $96(\mathbf{2 i})$ \\
10 & $\mathbf{1 j}-Z$ & $\mathrm{Cl}$ & $\mathrm{CH}$ & $\mathrm{H}$ & $\mathrm{Et}$ & ${ }^{\mathrm{t}} \mathrm{BuONa} / \mathrm{dppp}$ & $50^{\circ} \mathrm{C}, 15 \mathrm{~h}$ & $43(\mathbf{2 j})$ \\
11 & $\mathbf{1 k}$ & $\mathrm{Br}$ & $\mathrm{N}$ & $\mathrm{H}$ & $\mathrm{Ph}$ & ${ }^{\mathrm{t}} \mathrm{BuONa} / \mathrm{dppf}$ & $50^{\circ} \mathrm{C}, 13 \mathrm{~h}$ & $82(\mathbf{2 k})$
\end{tabular}

a) Reaction Conditions: 1 (1.0 equiv.), base (1.5 equiv.), $\mathrm{Pd}(\mathrm{OAc})_{2}(15 \mathrm{~mol} \%)$, and ligand (22.5 mol\%) in dioxane. $b$ ) Single isomer, geometry has not yet been determined otherwise noted. $c$ ) $\mathrm{Pd}_{2}(\mathrm{dba})_{3}$ was used instead of $\mathrm{Pd}(\mathrm{OAc})_{2}$.

Table 2. Intramolecular Pd-Catalyzed Cyclization of Oximes for Benzoisoxazoles Synthesis ${ }^{a)}$
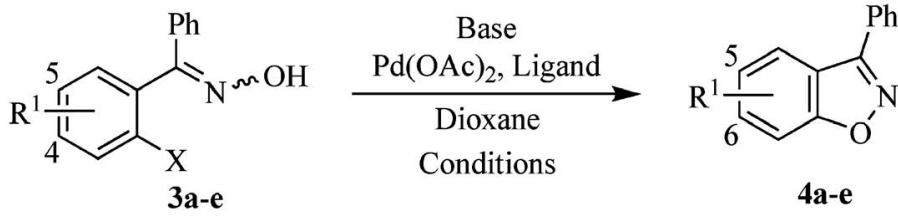

\begin{tabular}{clccccc}
\hline \hline Entry & $\mathbf{3}^{b)}$ & $\mathrm{X}$ & $\mathrm{R}^{1}$ & Base/Ligand & Conditions & Yield (\%) \\
\hline 1 & $\mathbf{3 a}$ & $\mathrm{Br}$ & $\mathrm{H}$ & ${ }^{\mathrm{t}} \mathrm{BuONa} / \mathrm{dppf}$ & $50^{\circ} \mathrm{C}, 62 \mathrm{~h}$ & $72(\mathbf{4 a})$ \\
2 & $\mathbf{3 b}$ & $\mathrm{Br}$ & $4-\mathrm{NO}_{2}$ & ${ }^{\mathrm{t}} \mathrm{BuONa} / \mathrm{dppf}$ & $\mathrm{rt}, 15 \mathrm{~h}$ & $67\left(\mathbf{4 b}: \mathrm{R}^{1}=6-\mathrm{NO}_{2}\right)$ \\
3 & $\mathbf{3 b}$ & $\mathrm{Br}$ & $4-\mathrm{NO}_{2}$ & ${ }^{\mathrm{t}} \mathrm{BuONa} / \mathrm{dppp}$ & $\mathrm{rt}, 6 \mathrm{~h}$ & $88\left(\mathbf{4 b}: \mathrm{R}^{1}=6-\mathrm{NO}_{2}\right)$ \\
4 & $\mathbf{3 c}$ & $\mathrm{Br}$ & $5-\mathrm{OMe}$ & ${ }^{\mathrm{t}} \mathrm{BuONa} / \mathrm{dppf}$ & $80^{\circ} \mathrm{C}, 34.5 \mathrm{~h}$ & $23(29)^{c)}\left(\mathbf{4 c}: \mathrm{R}^{1}=5-\mathrm{OMe}\right)$ \\
5 & $\mathbf{3 c}$ & $\mathrm{Br}$ & $5-\mathrm{OMe}$ & ${ }^{\mathrm{t}} \mathrm{BuONa} / \mathrm{dppp}$ & $80^{\circ} \mathrm{C}, 15 \mathrm{~h}$ & $36(10)^{c)}\left(\mathbf{4 c}: \mathrm{R}^{1}=5-\mathrm{OMe}\right)$ \\
6 & $\mathbf{3 d}$ & $\mathrm{ONf}$ & $\mathrm{H}$ & ${ }^{\mathrm{t}} \mathrm{BuONa} / \mathrm{dppf}$ & $80^{\circ} \mathrm{C}, 17.5 \mathrm{~h}$ & $14(\mathbf{4 d})$ \\
7 & $\mathbf{3 d}$ & $\mathrm{ONf}$ & $\mathrm{H}$ & ${ }^{\mathrm{C}} \mathrm{Cs}_{2} \mathrm{CO}_{3} / \mathrm{dppf}$ & $80^{\circ} \mathrm{C}, 4.5 \mathrm{~h}$ & $20(\mathbf{4 d})$ \\
8 & $\mathbf{3 e}$ & $\mathrm{Cl}$ & $\mathrm{H}$ & ${ }^{\mathrm{t}} \mathrm{BuONa} / \mathrm{dppf}$ & $80^{\circ} \mathrm{C}, 11 \mathrm{~h}$ & $67(20)^{c)}(\mathbf{4 e})$ \\
9 & $\mathbf{3 e}$ & $\mathrm{Cl}$ & $\mathrm{H}$ & ${ }^{\mathrm{t}} \mathrm{BuONa} / \mathrm{dppp}$ & $80^{\circ} \mathrm{C}, 8 \mathrm{~h}$ & $55(23)^{c)}(\mathbf{4 e})$
\end{tabular}

a) Reaction Conditions: 3 (1.0 equiv.), base (1.5 equiv.), $\mathrm{Pd}(\mathrm{OAc})_{2}(15 \mathrm{~mol} \%)$, and ligand (22.5 mol\%) in dioxane. $b$ ) Single isomer, geometry has not yet been determined. $c$ ) Recovery yield of starting material in parentheses.

ゾール環を骨格に持つ天然物は非常に稀であり，現 在までに nigellicine, nigellidine，及び nigeglanine の 3 種が単離報告されているのみである（Fig. 3).22-24)これらは Nigella sativa 及び Nigella glandulifera から単離・構造決定された化合物であり, これらを含む植物の種子は駆風作用，刺激作用，発 汗作用等を示すことが知られている。しかしなが ら，天然物そのものの生理活性作用については現在
までのところ報告がない。また，本系天然物の合成 研究としては，Kelly らによる最初の nigellicine 及 び nigeglanine の合成が報告されているのみであ る. ${ }^{25)}$ 筆者は，上述のパラジウム触媒インダゾール 合成を, nigellicine 合成に応用できるのではないか と考え，検討を行った（Fig. 4).

市販の 2,5-dimethylphenol 5 を既知の手法 ${ }^{26)}$ によ りアルデヒド $\mathbf{6}$ に導き，さらに KCN 存在下，ethyl 
<smiles></smiles>

Nigellicine<smiles>Cc1cc([O-])c2c(-c3ccc(O)cc3)[n+]3n(c2c1)CCCC3</smiles>

Nigellidine<smiles>Cc1cc([O-])c2c[n+]3n(c2c1)CCCC3</smiles>

Nigeglanine

Fig. 3. Naturally Occurring Indazole Derivatives

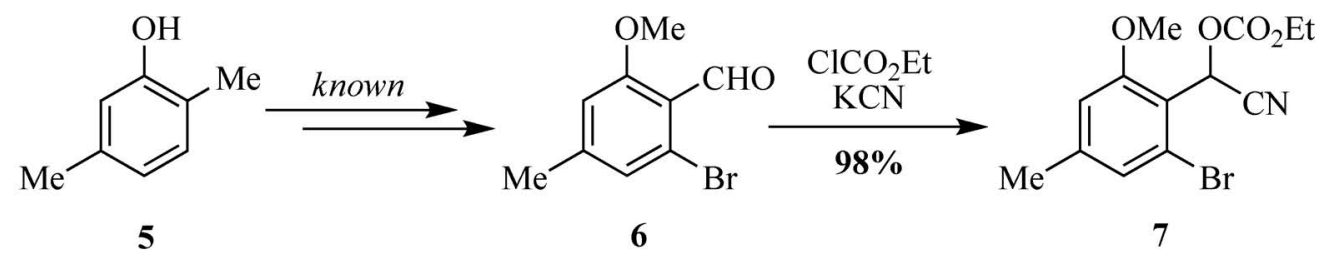

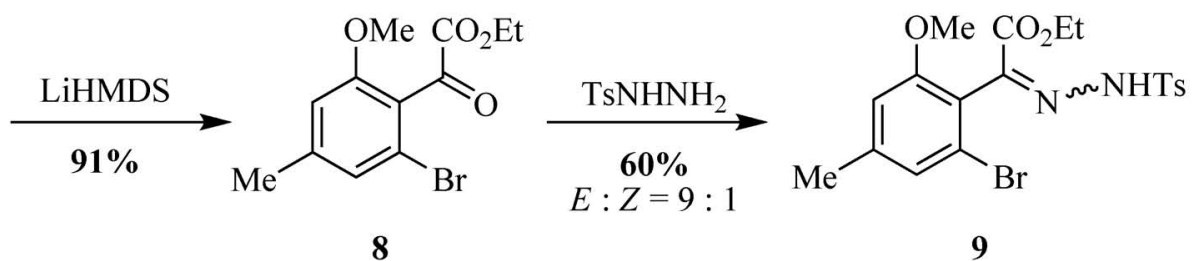<smiles>CCOC(=O)/C(=N/NS)c1c(Br)cc(C)cc1OC</smiles><smiles>CCOC(=O)c1nn([Tl])c2cc(C)cc(OC)c12</smiles>

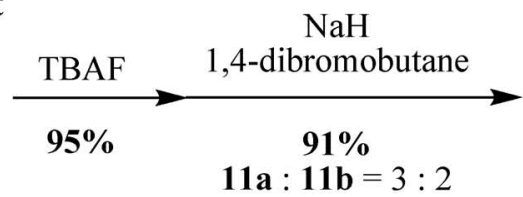<smiles>CCOC(=O)c1nn(CCCCBr)c2cc(C)cc(OC)c12</smiles>

11a

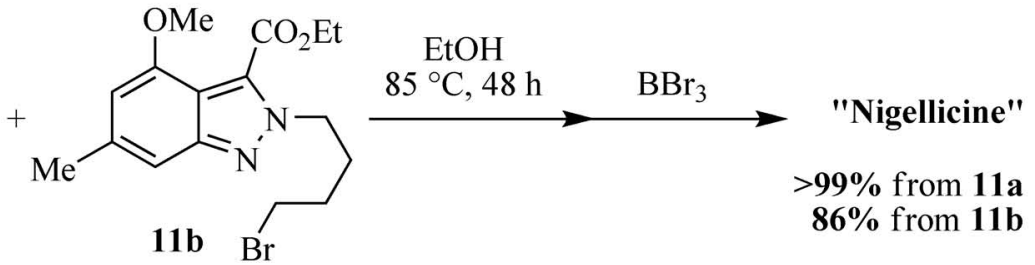

Fig. 4. Nigellicine Synthesis

chloroformate と反応させることによりシアノヒド リンカーボネートエステル 7 を合成した。 これを塩

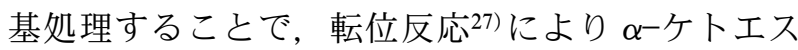
テル 8 とし, 続く $p$-tosylhydrazide との反応で鍵中 間体であるヒドラゾン 9 を $E: Z$ 比 $9: 1$ で得た。

このヒドラゾンの $E$ 体に対して, 分子内パラジウ 厶触媒アミノ化反応を適用したところ，塩基として $\mathrm{LiHMDS}$ 又は $\mathrm{K}_{3} \mathrm{PO}_{4}$ を用いることで, 中程度の収 率ではあるが望む位置に置換基を有するインダゾー
ル 10 が得られた。 10 の脱トシル化ののち 1,4dibromobutane と反応させることで， 1 位が $N$-ア ルキル化された化合物 11a と 2 位が $N$-アルキル化 された化合物 11bが， $3: 2$ という比で生成した. これらをそれぞれ $\mathrm{EtOH}$ 中で加熱して 2 度目のア ルキル化反応により閉環を行うことで三環性化合物 を得たのち, $\mathrm{BBr}_{3}$ を用いてエチルエステル部及び メチルエーテル部の脱アルキル化を行い, nigellicineの合成を達成した. 
3. パラジウム触媒 $\mathbf{C}$ 一 $\mathbf{H}$ アミノ化反応を利用し たインダゾール合成 ${ }^{19)}$

触媒的 $\mathrm{C}-\mathrm{H}$ 結合活性化と続く官能基化による 分子構築は，高効率的な分子変換法の開発という観 点からは基より, 省エネルギーや環境調和性に対す る社会的要請が高まっている現代において，最も理 想的な手法の 1 つであるといえる，筆者は，上述の インダゾール合成のさらなる展開として，パラジウ 厶触媒 $\mathrm{C}-\mathrm{H}$ 結合活性化と続く分子内アミノ化反 応を利用した新規インダゾール合成法の開発に着手 した（X=H in Fig. 2)，驚くべきことに，検討を 開始した時点での「パラジウム触媒 $\mathrm{C}-\mathrm{H}$ アミノ 化反応」に関する報告は 2 例あるのみであり, ${ }^{28,29)}$ そのいずれもが比較的高温条件 $\left(80-120^{\circ} \mathrm{C}\right)$ を用い ているため，官能基共存性に問題がある。また，ル テニウム ${ }^{30)}$ やロジウム ${ }^{31)}$ ，コバルト ${ }^{32)}$ といった他の 金属触媒を用いた同様の反応も何例か報告されてい るが，錯体調製に多段階要すること，錯体自体の安 定性，反応系から水・酸素を厳密に排除する必要性 などから，大量合成への適用が困難である場合が多 い．筆者はこれらの点を解決した合成プロセスの創 出を目的として，特に反応の実用的応用を考慮しつ つ，可能な限り穏和な条件下進行する，官能基共存 性の高いパラジウム触媒系の開発を念頭に置き検討 を行った。

\section{3-1. 最適条件の探索 Benzophenone tosyl-} hydrazone 12 を基質とし，パラジウム錯体として $50 \mathrm{~mol} \%$ の $\mathrm{Pd}(\mathrm{OAc})_{2}$, 再酸化剂として $100 \mathrm{~mol} \%$ の $\mathrm{Cu}(\mathrm{OAc})_{2}$ を用い， $120^{\circ} \mathrm{C}$ という反応温度で溶媒 効果に関する検討を行った (Table 3, Entries 1-8). その結果， MeCN や DMF, DMSO といつた極性溶 媒を用いることで，望むインダゾール閉環体 13 が 収率よく得られることが明らかとなった (Entries 68)。その中でも特に収率のよかった DMSO を用 い，続いて触媒量及び反応温度の低減化を試みた。 すると， $30 \mathrm{~mol} \%$ の $\mathrm{Pd}(\mathrm{OAc})_{2}$ 存在下，反応温度を $50^{\circ} \mathrm{C}$ まで下げても，収率よく生成物が得られるこ とが分かった（Entry 11）。しかしながら本条件に おいては，触媒量のさらなる低減化は，反応変換率 (conversion)の大幅な低下につながつた (Entry 12).

さらに最適化の検討を進めていく過程で，ある種 の銀塩の添加が本反応を大きく促進することを見い 出した（Table 4, Entries 8-11）。特に $\mathrm{AgOCOCF}_{3}$
Table 3. Optimization of Reaction Conditions 1 for $\mathrm{C}-\mathrm{H}$ Amination $^{a}$ )<smiles>[Nb]N=C(c1ccccc1)c1ccccc1</smiles>

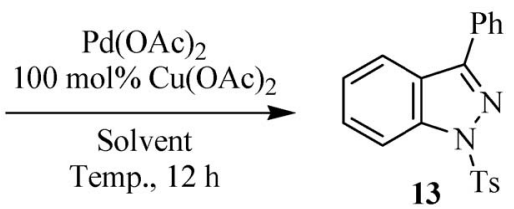

12

Temp., $12 \mathrm{~h}$

13 Ts

\begin{tabular}{ccccc}
\hline \hline Entry & $\mathrm{Pd}(\mathrm{OAc})_{2}(\mathrm{~mol} \%)$ & Solvent & Temp. $\left({ }^{\circ} \mathrm{C}\right)$ & Yield $(\%) b)$ \\
\hline 1 & 50 & Toluene & 120 & $18(16)$ \\
2 & 50 & Dioxane & 120 & $19(0)$ \\
3 & 50 & EtOH & 120 & $23(53)$ \\
4 & 50 & DCE & 120 & $15(23)$ \\
5 & 50 & AcOH & 120 & $51(0)$ \\
6 & 50 & MeCN & 120 & $73(0)$ \\
7 & 50 & DMF & 120 & $55(0)$ \\
8 & 50 & DMSO & 120 & $95(0)$ \\
9 & 30 & DMSO & 120 & $76($ trace $)$ \\
10 & 30 & DMSO & 80 & $76(7)$ \\
11 & 30 & DMSO & 50 & $85(0)$ \\
12 & 20 & DMSO & 50 & $58(30)$ \\
\hline
\end{tabular}

a) Reagents: $12(50 \mathrm{mg}), \mathrm{Pd}(\mathrm{OAc})_{2}$ (above), $\mathrm{Cu}(\mathrm{OAc})_{2}(100 \mathrm{~mol} \%)$, and solvent $(0.05 \mathrm{M}) . b$ ) Recovery yield of starting material in parentheses.

Table 4. Optimization of Reaction Conditions 2 for $\mathrm{C}-\mathrm{H}$ Amination ${ }^{a}$ )
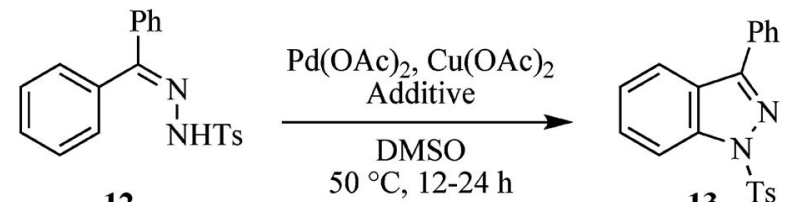

12

$50^{\circ} \mathrm{C}, 12-24 \mathrm{~h}$

\begin{tabular}{ccccc}
\hline \hline Entry & $\begin{array}{c}\mathrm{Pd}(\mathrm{OAc})_{2} \\
(\mathrm{~mol} \%)\end{array}$ & $\begin{array}{c}\mathrm{Cu}(\mathrm{OAc})_{2} \\
(\mathrm{~mol} \%)\end{array}$ & $\begin{array}{c}\text { Additive } \\
(\mathrm{mol} \%)\end{array}$ & $\begin{array}{c}\text { Yield } \\
(\%)^{b}\end{array}$ \\
\hline 1 & 20 & 100 & - & $58(30)$ \\
2 & 20 & 100 & $\mathrm{MS} 4 \AA(100 \mathrm{mg})$ & $65(20)$ \\
3 & 20 & 100 & $\mathrm{H}_{2} \mathrm{O}(1 \mathrm{drop})$ & $57(26)$ \\
4 & 20 & 100 & $\mathrm{Bu}_{4} \mathrm{NBr}(20)$ & $43(47)$ \\
5 & 20 & 200 & $\mathrm{Et}_{3} \mathrm{~N}(300)$ & $43(44)$ \\
6 & 20 & 200 & $\mathrm{Ag}_{2} \mathrm{O}(200)$ & $63(32)$ \\
7 & 20 & 200 & $\mathrm{AgBr}^{2}(200)$ & $45(35)$ \\
8 & 20 & 200 & $\mathrm{AgNO}_{3}(200)$ & $94(0)$ \\
9 & 20 & 200 & $\mathrm{Ag}_{2} \mathrm{CO}_{3}(200)$ & $88(0)$ \\
10 & 20 & 200 & $\operatorname{AgOAc}^{200)}$ & $62(34)$ \\
11 & 20 & 200 & $\mathrm{AgOCOCF}_{3}(200)$ & $94(0)$ \\
12 & 10 & 100 & $\mathrm{AgOCOCF}_{3}(200)$ & $90(0)$ \\
13 & 5 & 200 & $\mathrm{AgOCOCF}_{3}(200)$ & $58(37)$ \\
\hline
\end{tabular}

a) $12(50 \mathrm{mg}), \mathrm{Pd}(\mathrm{OAc})_{2}$ (above), $\mathrm{Cu}(\mathrm{OAc})_{2}$ (above), additive (above), and DMSO (0.05 M). b) Recovery yield of starting material in parentheses. 
の反応促進効果が大きく，これを $200 \mathrm{~mol} \%$ 用いた 場合に, $\mathrm{Pd}(\mathrm{OAc})_{2}$ を $10 \mathrm{~mol} \%$ にまで低減しても, 高収率で目的生成物が得られることが明らかとなつ た (Entry 12)。現在までのところ，この銀塩の効 果に関する明確な知見は得られていないものの, “ $\mathrm{Pd}(\mathrm{OAc})_{2}$ ”のみ, “ $\mathrm{Cu}(\mathrm{OAc})_{2}$ ”のみ, “ $\mathrm{AgOCOCF}_{3}$ ”

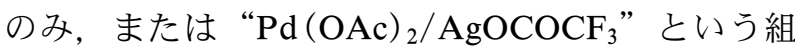
み合わせのいずれの条件においても収率の低下が観 測されたことから，“Pd ( OAc $)_{2} / \mathrm{Cu}(\mathrm{OAc})_{2} /$ $\mathrm{AgOCOCF}_{3} ”$ という組み合わせは必須であり，銀 塩は再酸化剂として働くとともに，触媒サイクルの いずれかの段階を活性化している可能性が示唆され る. ${ }^{33)}$ 今後の詳細な検討によりこの点を明らかにし たいと考えている.

\section{3-2. Pd/ Cu/Ag 触媒系の活性評価続いて,} 上述のようにして確立した $\mathrm{Pd}(\mathrm{OAc})_{2} / \mathrm{Cu}(\mathrm{OAc})_{2} /$ $\mathrm{AgOCOCF}_{3}$ 触媒系を用い，様々な置換様式を持つ ベンゾフェノン誘導体の閉環反応を行った.
まず，2つのベンゼン環それぞれに置換基が存在 する基質（14a-f）を用いて検討を行った（Table 5). 両方のベンゼン環のパラ位にメトキシ基を有する基 質（14a）の反応性は非常に低いが（Entry 1)，メ チル基を有する基質（14b）からは良好な収率で望 むインダゾール 15b が得られた（Entry 2)。興味深 いことに，2つのベンゼン環の両方のメタ位に存在 するメトキシ基は本閉環反応を非常に促進し, 定量 的に生成物 15c が得られた。 またこの基質において は，2つある反応点のうち，より立体障害の少ない 6 位でのみ反応が進行した．さらに，一方のベンゼ ン環のメ夕位にメトキシ基が，もう一方のベンゼン 環のメ夕位に電子求引性基 $\left(\mathrm{NO}_{2}, \mathrm{CN}\right.$, and $\left.\mathrm{CO}_{2} \mathrm{Et}\right)$ が置換した基質（14d，14e，and 14f）においては, メトキシ基の置換したベンゼン環上の 6 位でのみ閉 環反応が進行した化合物（15d, 15e, and 15f）を選 択的に得ることができた。（Entries 4-6）。これは本 閉環反応の選択性が，立体的要因とともに，ベンゼ

Table 5. Pd-Catalyzed Cyclization of Di-Substituted Benzophenone Tosylhydrazones ${ }^{a}$ )

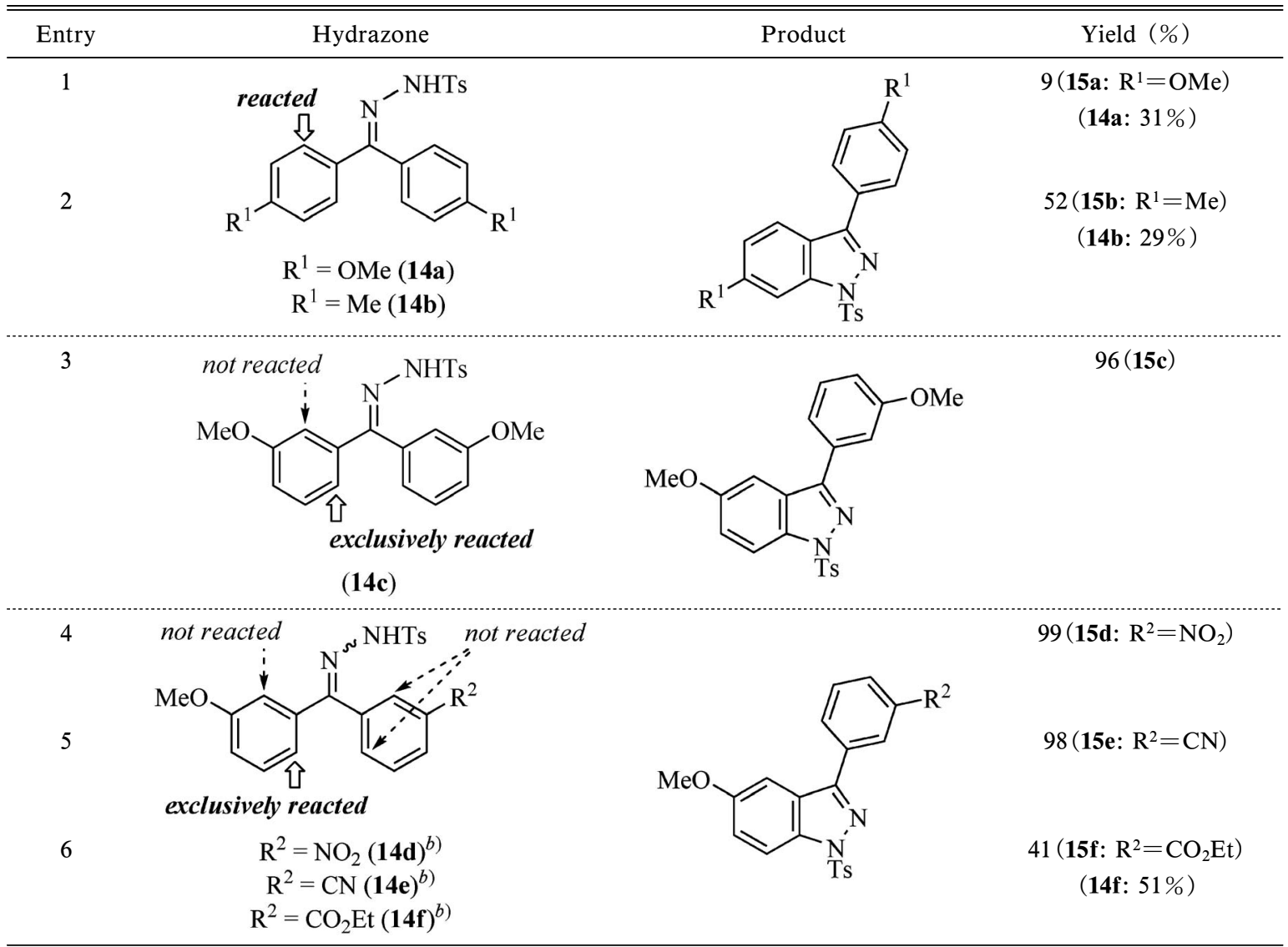

a) Reagents: $14(50 \mathrm{mg}), \mathrm{Pd}(\mathrm{OAc})_{2}(10 \mathrm{~mol} \%), \mathrm{Cu}(\mathrm{OAc})_{2}(100 \mathrm{~mol} \%), \mathrm{AgOCOCF}_{3}(200 \mathrm{~mol} \%)$, and DMSO, 50 $\left.{ }^{\circ} \mathrm{C}, 10-24 \mathrm{~h} . b\right) \mathrm{Single}$ isomer, geometry has not yet been determined. 
ン環上の電子的要因に大きく影響を受けていること を示している.

続いて，一方のベンゼン環上にのみ置換基を有す るヒドラゾン類に上記の触媒系を適用し，その活性 及び選択性について詳細に検討を行った（Table 6). メ夕位に置換基を有する基質（14g-14l）の反 応からは，おおむね良好な収率でインダゾール閉環 体（15g-15I）が得られた（Entries 1-6）。またここ でも，位置選択性がベンゼン環上の置換基に大きく 影響を受けていることが明らかとなった。例えば， 電子供与性基であるヒドロキシル基やアミノ基を有 する基質（14g and 14h）では，閉環反応は置換基 の存在するべンゼン環 $\left(\mathrm{A}^{1}\right)$ 上でのみ選択的に進 行した（Entries 1 and 2)。一方で, 電子求引性基を 持つヒドラゾン（14j, 14k, and 14l）においては, 無置換のベンゼン環 $\left(\mathrm{A}^{2}\right)$ 上で優先的に反応が進 行した（Entries 4-6). パラ位に置換基を有する基 質の反応性は一般的に低かった（Entries 7-9）もの の, Entry 8 と Entry 9 の結果の比較より, 本条件 下においては，反応系中でヒドラゾンの異性化が容 易に進行していることが示唆された。加えて，オル
卜位に臭素原子を有する基質（140）からは，脱八 ロゲン化したインダゾール 150 がほぼ定量的に得 られた (Entry 10)

さらに本反応の基質適用範囲の拡大を目指して検 討を行ったところ, 同様の触媒系を用いることで, 3 位にアルキル側鎖を有するインダゾール 17 が, 対応するヒドラゾン 16 から良好な収率で得られる ことが明らかとなっ (Fig. 5)。

\section{3-3. 反応機構に関する考察＼cjkstart現時点では，本} $\mathrm{C}$ - H アミノ化反応の反応機構を以下のように考え ている（Fig. 6)，先に述べたように，反応系中で のヒドラゾンの異性化は容易に起こると推察され る. 反応はまずヒドラゾンの窒素原子に 2 価のパラ ジウムが配向し, 続く芳香族求電子置換反応により, $\mathrm{C}$ - $\mathrm{H}$ 結合活性化を経由して 6 員環のパラダサイク ルが形成する。ヒドラゾン類のメタ位の電子供与性 基による反応性及び化学選択性の増大は，この芳香 族求電子置換反応の段階を促進していることに由来 していると考えられる．その後パラジウムの還元的 脱離により，インダゾール及び 0 価のパラジウムが 生成する．銅塩と銀塩がパラジウムの再酸化に関与

Table 6. Pd-Catalyzed Cyclization of Mono-Substituted Benzophenone Tosylhydrazones ${ }^{a}$ )

\begin{tabular}{|c|c|c|c|c|c|}
\hline Entry & Hydrazone $^{b)}$ & $\mathrm{R}$ & Yield (\%) & $\mathbf{1 4}(\%)$ & $\boldsymbol{a}: \boldsymbol{b}(: \boldsymbol{c})(\%)$ \\
\hline $1^{c)}$ & & $\mathrm{R}^{3}=\mathrm{OH}(\mathbf{1 4 g})$ & $75(15 g)$ & 0 & $75: 0$ \\
\hline $2^{c)}$ & & $\mathrm{R}^{3}=\mathrm{NH}_{2}(\mathbf{1 4 h})$ & $66(15 h)$ & 0 & $66: 0$ \\
\hline 3 & & $\mathrm{R}^{3}=\mathrm{OMe}(\mathbf{1 4} \mathbf{i})$ & $81(\mathbf{1 5 i})$ & 3 & $56: 28$ \\
\hline 4 & & $\mathrm{R}^{3}=\mathrm{Cl}(\mathbf{1 4} \mathbf{j})$ & $84(\mathbf{1 5} \mathbf{j})$ & 0 & $19: 65$ \\
\hline 5 & & $\mathrm{R}^{3}=\operatorname{Br}(\mathbf{1 4 k})$ & $79(15 k)$ & $9(14 k)$ & $37: 49$ \\
\hline 6 & & $\mathrm{R}^{3}=\mathrm{NO}_{2}(14 \mathrm{l})$ & $32(15 l)$ & $26(141)$ & $0: 43$ \\
\hline $7^{c)}$ & & $\mathrm{R}^{4}=\mathrm{NO}_{2}(\mathbf{1 4 m})$ & $27(15 \mathrm{~m})$ & $27(14 m)$ & $0: 37$ \\
\hline 8 & & $\begin{array}{l}\mathrm{R}^{4}=\mathrm{OMe}(\mathbf{1 4 n}) \\
(E: Z=1: 0.04)\end{array}$ & $22(15 n)$ & $57(14 n)$ & $14: 37$ \\
\hline 9 & & $\begin{array}{l}\mathrm{R}^{4}=\mathrm{OMe}(\mathbf{1 4 n}) \\
(E: Z=0.31: 1)\end{array}$ & $31(\mathbf{1 5 n})$ & $52(14 n)$ & $29: 35$ \\
\hline 10 & & $\mathrm{R}^{5}=\mathrm{Br}(\mathbf{1 4 0})$ & $98(\mathbf{1 5 0})$ & 0 & $0: 0: 98$ \\
\hline
\end{tabular}

a) Reagents: $14(50 \mathrm{mg}), \mathrm{Pd}(\mathrm{OAc})_{2}(10 \mathrm{~mol} \%), \mathrm{Cu}(\mathrm{OAc})_{2}(100 \mathrm{~mol} \%), \mathrm{AgOCOCF}_{3}(200 \mathrm{~mol} \%)$, and DMSO, 50 $\left.0^{\circ} \mathrm{C}, 10-24 \mathrm{~h} . b\right) \mathrm{Single}$ isomer, geometry has not yet been determined. c) $80^{\circ} \mathrm{C}$. 
<smiles>NN=C(Br)c1ccccc1</smiles>

16

(single isomer)

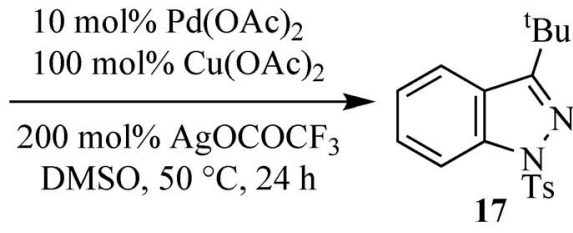

$97 \%$ conversion yield $66 \%$ isolated yield $(16: 32 \%)$

Fig. 5. 3-Alkylindazole Synthesis

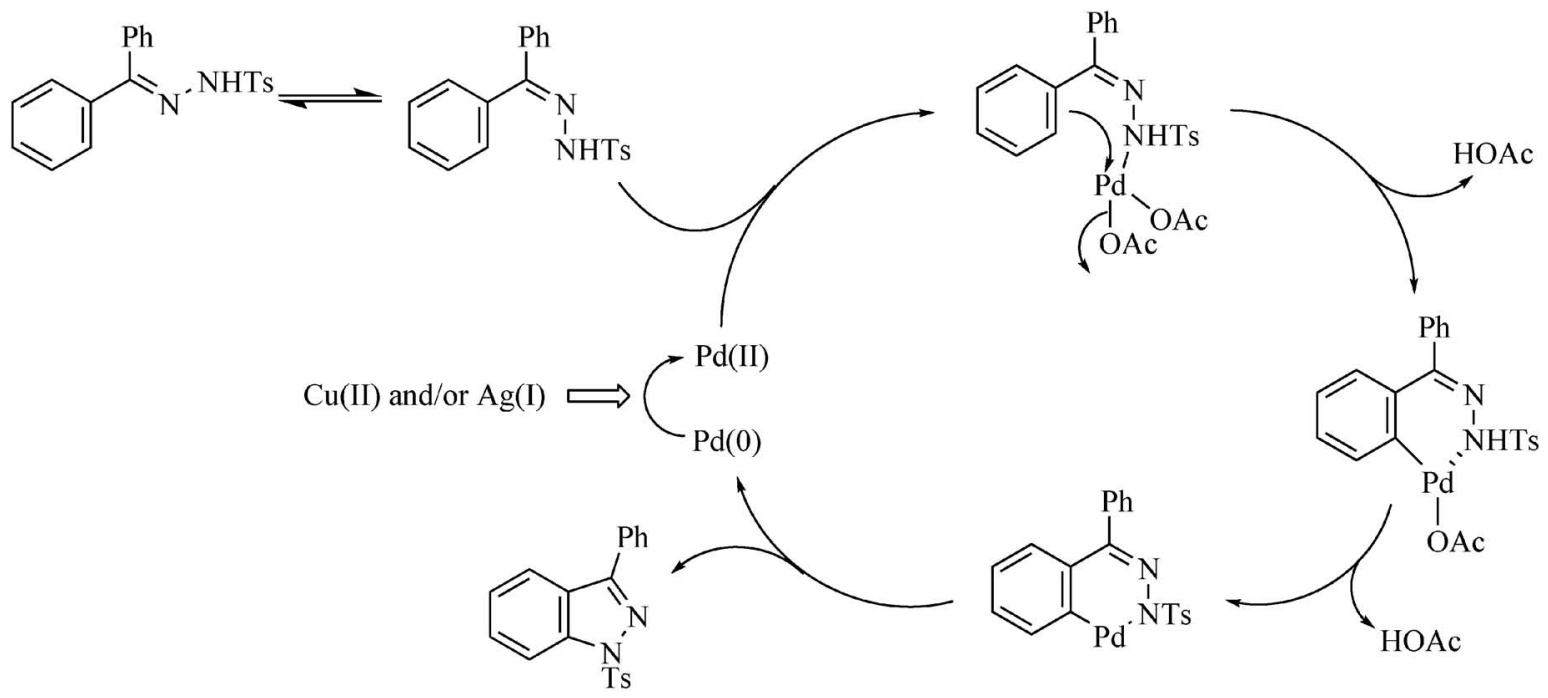

Fig. 6. Postulated Reaction Mechanism

していると予想されるが，詳細については不明であ る。

\section{4. おわりに}

以上示してきたように, 分子内パラジウム触媒 $\mathrm{C}$ - $\mathrm{X}$ アミノ化反応および $\mathrm{C}-\mathrm{H}$ アミノ化反応とい う2つの反応を用いることで，幅広い置換様式を有 するインダゾール環を効率的に得る方法を見い出し た. ぞちらの手法も，これまでのものに比べて非常 に穏和な条件下進行し，同時に高い官能基共存性を 実現できた。特に後者の反応は，出発物質の入手容 易さを考慮すれば，今後広範な複素環化合物合成へ 応用できると考えられ，その結果が様々な分野に寄 与できることを期待したい.

謝辞本研究は, 東北大学大学院薬学研究科反 応制御化学分野において行われたものであり，同分 野の坂本尚夫前教授及び廣谷 功准教授には終始御 指導，御鞭撻を頂きました。ここに厚く御礼申し上
げます。

\section{REFERENCES}

1) Cerecetto H., Gerpe A., Gonzalez M., Aran V. J., de Ocariz C. O., Mini-Rev. Med. Chem., 5, 869-878 (2005).

2) Hwang T.-L., Ahuo S.-K., Pan Y.-L., Eur. J. Pharmacol., 579, 395-402 (2008).

3) Lee Y.-K., Parks D. J., Lu T., Thieu T. V., Markotan T., Pan W., McComsey D. F., Milkiewicz K. L., Crysler C. S., Ninan N., Abad M. C., Giardino E. C., Maryanoff B. E., Damiano B. P., Player M. R., J. Med. Chem., 51, 282-297 (2008).

4) Moreira V. M. A., Vasaitis T. S., Njar V. C. O., Salvador J. A. R., Steroids, 72, 939-948 (2007).

5) Martin N. I., Derbyshire E. R., Marletta M. A., Bioorg. Med. Chem. Lett., 17, 4938-4941 (2007). 
6) Park J. S., Yu K. A., Kang T. H., Kima S., Suha Y.-G., Bioorg. Med. Chem. Lett., 17, 3486-3490 (2007).

7) Yakaiah T., Lingaiah B. P. V., Narsaiah B., Shireesha B., Kumar B. A., Gururaj S., Parthasarathy T., Sridhar B., Bioorg. Med. Chem. Lett., 17, 3445-3453 (2007).

8) Giannouli V., Kostakis I. K., Pouli N., Marakos P., Kousidou O. C., Tzanakakis G. N., Karamanos N. K., J. Med. Chem., 50, 1716-1719 (2007).

9) Groessl M., Reisner E., Hartinger C. G., Eichinger R., Semenova O., Timerbaev A. R., Jakupec M. A., Arion V. B., Keppler B. K., J. Med. Chem., 50, 2185-2193 (2007).

10) Gupta A. K., Jain A., Agrawal K., Saraswat V., Revathi S., Soni L. K., Kaskhedikar S. G., Med. Chem., 3, 347-353 (2007).

11) Schujmann P., Collot V., Hommet Y., Gsell W., Dauphin F., Sopkova J., MacKenzie E., Duval D., Boulouard M., Rault S., Bioorg. Med. Chem. Lett., 11, 1153-1156 (2001).

12) Bartsch R. A., Yang I. W., J. Heterocycl. Chem., 21, 1063-1064 (1984).

13) Gladstone W. A. S., Norman R. O. C., J. Chem. Soc., 3048-3052 (1965).

14） Song J. J., Yee N. K., Org. Lett., 2, 519-521 (2000).

15) Cho C. S., Lim D. K., Heo N. H., Kim T. J., Shim S. C., Chem. Commun., 104-105 (2004)

16) Lebedev A. Y., Khartulyari A. S., Voskoboynikov A. Z., J. Org. Chem., 70, 596-602 (2005).

17) Inamoto K., Katsuno M., Yoshino T., Suzuki I., Hiroya K., Sakamoto T., Chem. Lett., 33, 1026-1027 (2004).

18) Inamoto K., Katsuno M., Yoshino T., Arai Y., Hiroya K., Sakamoto T., Tetrahedron, 63,
2695-2711 (2007).

19) Inamoto K., Saito T., Katsuno M., Sakamoto T., Hiroya K., Org. Lett., 9, 2931-2934 (2007).

20) Hartwig J. F., Synlett, 1283-1294 (2006).

21) Anderson K. W., Mendez-Perez M., Priego J., Buchwald S. L., J. Org. Chem ., 68, 9563-9573 (2003).

22) Atta-ur-Rahman, Malik S., Cun-heng H., Clardy J., Tetrahedron Lett., 26, 2759-2762 (1985).

23) Atta-ur-Rahman, Malik S., Hasan S. S., Choudhary M. I., Ni C.-Z., Clardy J., Tetrahedron Lett., 36, 1993-1996 (1995).

24) Liu Y.-M., Yang J.-S., Liu Q.-H., Chem. Pharm. Bull., 52, 454-455 (2004).

25) Elliott E. L., Bushell S. M., Cavero M., Tolan B., Kelly T. R., Org. Lett. 7, 2449-2451 (2005).

26) Clive D. L. J., Yu M., Chem. Commun., 23802381 (2002).

27) Thasana N., Prachyawarakorn V., Tontoolarug S., Ruchirawat S., Tetrahedron Lett., 44, 1019-1021 (2003).

28) Tsang W. C. P., Zheng N., Buchwald S. L., J. Am. Chem. Soc., 127, 14560-14561 (2005).

29) Thu H.-Y., Yu W.-Y., Che C.-M., J. Am. Chem. Soc., 128, 9048-9049 (2006).

30) Lin X., Che C.-M., Phillips D. L., J. Org. Chem., 73, 529-537 (2008).

31) Liang C., Collet F., Robert-Pillard F., Müller P., Dodd R. H., Dauban P., J. Am. Chem. Soc., 130, 343-350 (2008).

32) Harden J. D., Ruppel J. V., Gao G.-Y., Zhang X. P., Chem. Commun., 4644-4646 (2007).

33) Yang S., Li B., Wan X., Shi Z., J. Am. Chem. Soc., 129, 6066-6067 (2007). 